\title{
Prophylactic Intratracheal Polymyxin B/Surfactant Prevents Bacterial Growth in Neonatal Escherichia coli Pneumonia of Rabbits
}

\author{
GUIDO STICHTENOTH, BIM LINDERHOLM, MARIE HÄGERSTRAND BJÖRKMAN, GABI WALTER, TORE CURSTEDT, \\ AND EGBERT HERTING
}

\author{
Department of Molecular Medicine and Surgery [G.S., B.L., M.H.B., T.C.], Karolinska Institutet, SE-17176 Solna, Sweden; Department of \\ Pediatrics [G.W., E.H.], University of Lübeck, D-23538 Lübeck, Germany
}

\begin{abstract}
In neonatal pneumonia, the surface activity of pulmonary surfactant is impaired and microorganisms may invade by passing the air-liquid interface. Previously, we have shown that addition of the antimicrobial peptide polymyxin $\mathrm{B}(\mathrm{PxB})$ to modified porcine surfactant (pSF) improves resistance to surfactant inactivation in vitro while antimicrobial activity of $\mathrm{PxB}$ is maintained. In this study, we investigated $\mathrm{pSF} / \mathrm{PxB}$ in vivo. Neonatal near-term rabbits were treated with intratracheal $\mathrm{pSF}$ and/or PxB. Rabbits treated with only saline served as controls. Animals were ventilated with standardized tidal volumes and received $\sim 10^{7}$ Escherichia coli intratracheally. Plethysmographic pressure-volume curves were recorded every $30 \mathrm{~min}$. After $240 \mathrm{~min}$, animals were killed, the right lung and left kidney were excised, and bacterial growth was determined. The left lung was used for histologic analysis. Intratracheal administration of $\mathrm{PxB} \pm \mathrm{pSF}$ significantly reduced the growth of $E$. coli compared with control animals or animals receiving only pSF. This was accompanied by reduction of severe inflammatory tissue destruction and significantly reduced bacterial translocation to the left kidney. Animals receiving $\mathrm{pSF}+\mathrm{PxB}$ had no difference in lung compliance compared with the pSF- or PxB-treated group. Mixtures of PxB and pulmonary surfactant show antimicrobial effects in neonatal rabbits and prevent systemic spreading of E. coli. (Pediatr Res 67: 369-374, 2010)
\end{abstract}

$\mathrm{P}$ lymyxins are cyclic antimicrobial peptides derived from Bacillus polymyxa with activity against a wide spectrum of Gram-negative bacteria including those considered to be multiresistant, e.g. Pseudomonas aeruginosa. Pharmacologically, rarely they are used for systemic application because nephrotoxic and neurotoxic effects have been described $(1,2)$. However, polymyxins are topically administered. For treat-

Received June 2, 2009; accepted November 25, 2009.

Correspondence: Guido Stichtenoth, M.D., Ph.D., Department of Pediatrics, University of Lübeck, Ratzeburger Allee 160, D-23538 Lübeck, Germany; e-mail: stichtenoth@paedia.ukl.mu-luebeck.de

Supported by the Swedish Research Council (Project No. 3351), The Swedish Heart Lung Foundation and the German Research Council (DFG He 2072/2-2) and the PPP-Program of the German Academic Exchange Service, DAAD, Project No.: PPP-SE and Chiesi Farmaceutici S.p.A.

T.C. has an annual grant for research regarding new synthetic surfactant preparations for clinical use and Co-author patent application with Chiesi Farmaceutici. E.H. has participated in surfactant trials conducted by Abbott/Ross Laboratories, Chiesi/ Nycomed, Boehringer/Thomae and Altana/Byk Gulden/Nycomed, and has received speaking fees/travel support from these companies. E.H. has a pending grant application for a multicenter study on surfactant application by gastric tube, supported by Chiesi Farmaceutici, and is a member of a scientific advisory board of Chiesi Farmaceutici, Dräger Medical and Nycomed. ment of chronic Gram-negative pneumonia, as in cystic fibrosis, polymyxin $\mathrm{E}$ or polymyxin $\mathrm{B}(\mathrm{PxB})$ is deposited in the lungs by inhalation.

Pulmonary surfactant is a lipoprotein complex aligning the alveolar air-liquid interface with the main function to reduce surface tension and thereby preventing alveolar collapse at end expiration (3). In neonatal pneumonia and meconium aspiration syndrome (MAS), surfactant function can be inhibited by the presence of bacterial or meconium components. Thus, bacterial enzymatic break down of surfactant components, pulmonary inflammation, and reduced surfactant synthesis due to alveolar type II cell injury can be induced (4). This may result in acute respiratory distress syndrome (ARDS). Surfactant replacement therapy is used in MAS, in neonatal pneumonia, and has been tested in ARDS in large clinical trials with promising effects in a subgroup with pneumonia (5).

Our group previously found that addition of PxB to modified porcine surfactant (pSF) increases resistance to meconiuminduced surfactant inactivation in vitro while the antimicrobial function of $\mathrm{PxB}$ is maintained (6). Thus, the combination of PxB and surfactant might be useful in clinical conditions such as neonatal Gram-negative pneumonia, MAS, or ARDS. It is unknown which effects a mixture of pSF/PxB may exert, whether pSF can be used as an effective vehicle for PxB or to which extent pSF/PxB improves lung compliance and enhances antimicrobial effects in vivo. The aim of this study was to address these questions in an animal model of neonatal Escherichia coli pneumonia.

\section{MATERIALS AND METHODS}

Bacteria. After preincubation for $16 \mathrm{~h}$ at $37^{\circ} \mathrm{C}$ in a small volume of standardized bouillon (standard I; dissolved to $25 \mathrm{mg} / \mathrm{L}$ in water; Merck 7882 , Merck, Darmstadt, Germany; composition: peptones $15 \mathrm{~g} / \mathrm{L}$; yeast extract 3 $\mathrm{g} / \mathrm{L}$; sodium chloride $6 \mathrm{~g} / \mathrm{L} ; \mathrm{D}(+)$ glucose $1 \mathrm{~g} / \mathrm{L}$ ), E. coli (ATTC 25922) reached a mid-logarithmic growth phase during incubation for $1 \mathrm{~h}$ in bouillon excess at $37^{\circ} \mathrm{C}$ (data of bacterial growth studies not shown). Then, a bacterial stock solution was prepared by centrifugation at $2500 \times \mathrm{g}$ for $10 \mathrm{~min}$, twice washing the E. coli in saline and adjusting the bacterial concentration by means of the OD at $595 \mathrm{~nm}$ to $\sim 10^{8} / \mathrm{mL}$.

\footnotetext{
Abbreviations: ARDS, acute respiratory distress syndrome; CFU, colonyforming units; LPS, lipopolysaccharide, endotoxin; pSF, modified porcine surfactant; PxB, polymyxin B; $\boldsymbol{V}_{\mathbf{T}}$, tidal volume
} 
Surfactant preparations. Modified pSF $80 \mathrm{mg} / \mathrm{mL}$ was derived from Chiesi Farmaceutici, Parma, Italy (Curosurf). PxB (Sigma Chemical Co. Aldrich; >6000 Units/mg) was suspended at 80,40 , and $20 \mathrm{mg} / \mathrm{mL}$ in saline and mixed with $\mathrm{pSF}$ at a ratio 1:100, thus giving preparations of $\mathrm{pSF} / \mathrm{PxB} 1 \%$, $0.5 \%$, and $0.25 \%$ (wt/wt). Thus, the final surfactant concentration decreased to $79.2 \mathrm{mg} / \mathrm{mL}$.

Animal experiments. Thirteen New Zealand White rabbits were anesthetized by diazepam $5 \mathrm{mg} / \mathrm{kg}$ s.c. and fentanyl/fluanisone $(0.315 / 10 \mathrm{mg} / \mathrm{mL}) 0.3$ $\mathrm{mL} / \mathrm{kg}$ i.m. Pups at a gestational age of $29 \mathrm{~d}$ (i.e. near term) were obtained by hysterotomy, anesthetized with pentobarbital $20 \mathrm{mg} / \mathrm{kg}$ i.p., and tracheotomized. Two experimental series were conducted with five treatment groups, respectively. The first series was designed to evaluate the effects of $\mathrm{pSF} / \mathrm{PxB}$ $1 \%$ compared with $\mathrm{pSF}$ or PxB. Saline $(2.5 \mathrm{~mL} / \mathrm{kg})$-treated animals were subdivided into groups receiving subsequently, at $15 \mathrm{~min}, 5 \mathrm{~mL} / \mathrm{kg}$ saline (=saline group), or $5 \mathrm{~mL} / \mathrm{kg} \mathrm{E}$. coli bacteria (control group) to compare the effects of fluid and bacterial load separately. The second series was designed to study dose-dependent effects of addition of $(0.25,0.5$ and $1 \%) \mathrm{PxB}$ to $\mathrm{pSF}$. Saline $(2.5 \mathrm{~mL} / \mathrm{kg})$-treated animals receiving subsequently E. coli $(5 \mathrm{~mL} / \mathrm{kg})$ served as control (control group). All surfactant-treated animals received 2.5 $\mathrm{mL} / \mathrm{kg}$ of $\mathrm{pSF} \pm \mathrm{PxB}$ equivalent to $200 \mathrm{mg}$ surfactant phospholipids per $\mathrm{kg}$. Animals were relaxed with $0.8 \mathrm{mg} / \mathrm{kg}$ pancuronium bromide and ventilated for $4 \mathrm{~h}$ (fraction of inspired oxygen $\left[\mathrm{FiO}_{2}\right]=1.0$ ) at a frequency of 40 inspirations/min and an inspiration/expiration ratio of 0.33 . Initially, the lungs were opened with five inspirations at a peak insufflation pressure of $35 \mathrm{~cm}$ $\mathrm{H}_{2} \mathrm{O}$, then a standardized tidal volume $\left(V_{\mathrm{T}}\right)$ of $6-7 \mathrm{~mL} / \mathrm{kg}$ was adjusted by means of a computerized multiplethysmograph system $(7,8) . V_{\mathrm{T}}$, peak insufflation pressures, and ECGs were recorded every $30 \mathrm{~min}$ and before bacterial inoculation. After $15 \mathrm{~min}$, animals were inoculated with $(5 \mathrm{~mL} / \mathrm{kg}) \mathrm{E}$. coli stock intratracheally with exception of the saline group of the first series. Then, the lung opening maneuver was repeated. After $4 \mathrm{~h}$, tracheal cannulas were clamped at end expiration. Animals were killed and the abdomens were opened to inspect diaphragms for evidence of pneumothorax and the lungs were carefully excised. The bacterial load was determined from the right lung and in the second series additionally from the left kidney. The left lung was processed for histologic evaluation (9).

Determination of bacterial growth. Right and left lungs as well as the left kidneys were weighed in sterile glass tubes. Saline was added to normalize weight to $1 \mathrm{~g}$. Then, the samples were homogenized using an OMNI/THhomogenizer (Omni International, Marietta, GA) with sterile tips. After serial dilution in saline, $100 \mu \mathrm{L}$ aliquots were transferred to Petri dishes, mixed with warm Columbia agar base (Oxoid CM 331-550 g) containing 5\% (vol/vol) defibrinated sheep blood, and incubated for $24 \mathrm{~h}$ at $37^{\circ} \mathrm{C}$. Then, the colonyforming units (CFU)/dish were counted. Either the Petri dishes of the homogenate, when CFU count was $0-250$, or the dishes of the diluted homogenate next to the homogenate showing 10-250 CFU were considered for evaluation (average count from duplicate dilutions).

Histologic analysis. Alveolar air expansion was semiquantitatively estimated by a five-grade scale $(1=0,2=1-25,3=26-50,4=51-75,5=$ $76-100 \%$ ), the grade of inflammation (absent, mild moderate, prominent, and severe tissue destruction), and airway epithelial necrosis (absent, mild, moderate, and prominent) by a four-grade scale.

Data analysis. Lung compliance of animals was calculated by dividing $V_{\mathrm{T}}$ by peak insufflation pressure and body weight. Survival of animals was considered when ECG showed a heart rate of $>60 / \mathrm{min}$. Results were calculated for all animals, nonsurvivors were not excluded. Statistical analysis was performed using GraphPad 4.02 software (San Diego, CA). Nonparametric data were analyzed by Kruskal-Wallis test, followed by Dunn's post-test and compliance data by repeated measures ANOVA followed by Bonferroni's multiple comparison test.

Experiments were approved by the local ethical committee, Stockholms Norra Djurförsöksetiska Nämnd, N205/04 and N316/06.

\section{RESULTS}

General data. Ninety-four animals were obtained, four animals were excluded due to air leaks or technical problems. Eight to 10 animals were randomly allocated to each treatment group. There was no statistical difference in body weight and lung/body weight within the treatment groups. Survival was low (22-60\%) without statistical differences within the series.

Lung function. In general, compliance values were low and showed a wide range within the groups with a tendency to decrease over time (Tables 1 and 2). Compared with the
Table 1. Compliance $\left[\mathrm{mL} /\left(\mathrm{kg} \cdot \mathrm{cm} \mathrm{H}_{2} \mathrm{O}\right)\right]$ data (median and range) of animals ventilated with tidal volumes of 6-7 $\mathrm{mL} / \mathrm{kg}$ body weight for 240 min, which received saline, pSF, and/or PxB $1 \%$ after birth and at $15 \mathrm{~min} 5 \mathrm{~mL} / \mathrm{kg}$ E. coli $\left(10^{8} / \mathrm{mL}\right)$

\begin{tabular}{llll}
\hline \multicolumn{1}{c}{ Treat } & \multicolumn{1}{c}{$10 \mathrm{~min}$} & \multicolumn{1}{c}{$60 \mathrm{~min}$} & \multicolumn{1}{c}{$240 \mathrm{~min}$} \\
\hline Saline & $0.43(0.24-0.70)^{*}$ & $0.35(0.30-0.55)$ & $0.30(0.20-0.56)$ \\
Control & $0.30(0.30-0.54)$ & $0.31(0.25-0.50)$ & $0.28(0.16-0.63)$ \\
PxB 1\% & $0.38(0.25-0.52) \dagger$ & $0.33(0.28-0.50)^{*}$ & $0.30(0.24-0.32)$ \\
pSF & $0.47(0.30-0.56)$ & $0.48(0.30-0.56)$ & $0.41(0.32-1.06)$ \\
+ PxB 1\% & $0.42(0.30-0.54)$ & $0.42(0.30-0.56)$ & $0.38(0.26-0.56)$ \\
\hline
\end{tabular}

Effects of pulmonary fluid load were studied in pups receiving twice saline and no bacteria (saline): $* p<0.05$ vs $240 \mathrm{~min} ; \dagger p<0.01$ vs $240 \mathrm{~min}$ (repeated measures ANOVA, Bonferroni's multiple comparison test).

Table 2. Compliance $\left[\mathrm{mL} /\left(\mathrm{kg} \cdot \mathrm{cm} \mathrm{H}_{2} \mathrm{O}\right)\right]$ data (median and range) of animals during ventilation for $4 h$, which received $p S F \pm P x B$ $0.25-1 \%$ after birth and at $15 \mathrm{~min} 5 \mathrm{~mL} / \mathrm{kg}$ E. coli $\left(10^{8} / \mathrm{mL}\right)$

\begin{tabular}{lcll}
\hline \multicolumn{1}{c}{ Treat } & \multicolumn{1}{c}{$10 \mathrm{~min}$} & \multicolumn{1}{c}{$60 \mathrm{~min}$} & \multicolumn{1}{c}{$240 \mathrm{~min}$} \\
\hline Control & $0.41(0.25-0.55)^{*}$ & $0.32(0.27-0.43)$ & $0.28(0.22-0.43)$ \\
pSF & $0.45(0.37-0.50)^{*}$ & $0.42(0.30-0.50)$ & $0.41(0.33-0.44)$ \\
+ PxB 0.25\% & $0.45(0.31-0.71)$ & $0.47(0.29-0.60) \dagger$ & $0.43(0.30-0.52) \dagger$ \\
+ PxB 0.5\% & $0.46(0.36-0.58)$ & $0.48(0.30-0.53) \dagger$ & $0.38(0.25-0.57)$ \\
+ PxB 1\% & $0.39(0.29-0.47)$ & $0.39(0.28-0.57)$ & $0.34(0.28-0.58)$ \\
\hline
\end{tabular}

$* p<0.05$ vs $240 \mathrm{~min}$ (repeated measures ANOVA, Bonferroni's multiple comparison test).

$\dagger p<0.05 v s$ control (one-way ANOVA, Bonferroni's multiple comparison test).

compliance at $10 \mathrm{~min}$, significantly reduced lung compliance was found after $4 \mathrm{~h}$ in the saline group and in the only PxB-treated group (Table 1) as well as in the control and the pSF group of the second series (Table 2). Animals receiving pSF + PxB showed no such tendency to reduce compliance over time. Compliance of pSF- \pm PxB-treated animals was slightly increased compared with controls (Tables 1 and 2). After 1 and $4 \mathrm{~h}$ in the second series, compliance of pSF- + PxB-treated animals was significantly increased (in group $\mathrm{pSF}+\mathrm{PxB} 0.25 \%$ at $60 \mathrm{~min}$ and $240 \mathrm{~min}$; in group pSF + $\mathrm{PxB} 0.5 \%$ at $60 \mathrm{~min}$ ) compared with the control group $(p<0.05$; Table 2).

Bacterial proliferation. Bacterial stock concentration of both series was similar with a mean of $3.2 \times 10^{8} \mathrm{E}$. coli $/ \mathrm{mL}$ in the first and $4.8 \times 10^{8}$ E. coli $/ \mathrm{mL}$ in the second series. At the end of the experiments, the bacterial count in lungs of animals receiving only $\mathrm{PxB}$ or $\mathrm{pSF} / \mathrm{PxB} 1 \%$ was significantly reduced compared with control animals and rabbits receiving pSF (Fig. 1 and 2). Moreover, the bacterial load was reduced in a PxB concentration-dependent manner (Fig. 2). In addition, the bacterial load of animals treated with pSF $+\mathrm{PxB} \geq 0.5 \%$ was significantly reduced compared with pups treated with only pSF. In the second series, we found E. coli in the homogenate of the left kidney in 7 of 10 control animals and in 3 of 9 pSFtreated animals, but we found no bacterial contamination in any animal treated with $\mathrm{pSF} / \mathrm{PxB}(p<0.01)$.

Histology. Gross inspection of the lungs showed atelectasis and hemorrhage. Histologic analysis of both experimental series revealed improved expansion in animals receiving only $\mathrm{pSF}$ or $\mathrm{pSF}+\mathrm{PxB}$ (Table 3) with exception of the $\mathrm{pSF} / \mathrm{PxB}$ $1 \%$ group of the second series (Table 3 ). Airway epithelial necrosis was found in all treatment groups with a wide range 


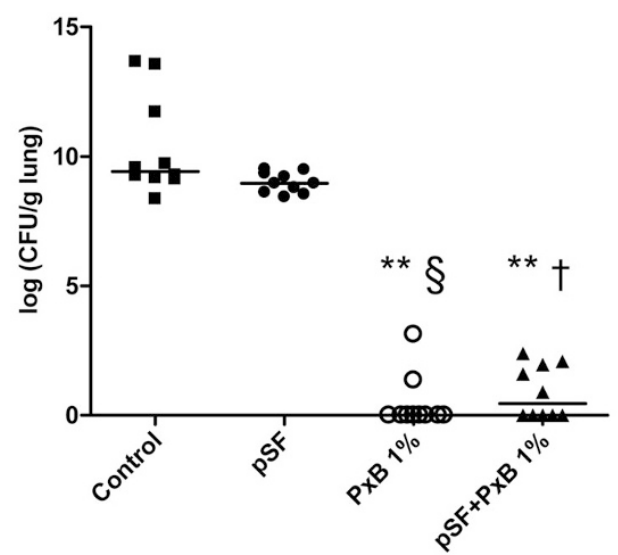

Figure 1. Logarithm of colony-forming units (CFU/g lung) in animals prophylactically receiving saline (control), surfactant $(\mathrm{pSF})$, only PxB $1 \%$ or $\mathrm{pSF}+\mathrm{PxB} 1 \%$ followed by bacterial inoculation of $10^{8} / \mathrm{mL}$ E. coli $(5 \mathrm{~mL} / \mathrm{kg})$ and ventilated for $240 \mathrm{~min}$ with standardized tidal volume of $6-7 \mathrm{~mL} / \mathrm{kg}$. Results were corrected by addition of $1 \mathrm{CFU}$ to enable calculation of the logarithm for those showing total bacterial eradication. $* * p<0.001 v s$ control; $\uparrow p<0.05 ; \S p<0.01$ vs pSF (nonparametric Kruskal-Wallis test with Dunn's post-test).

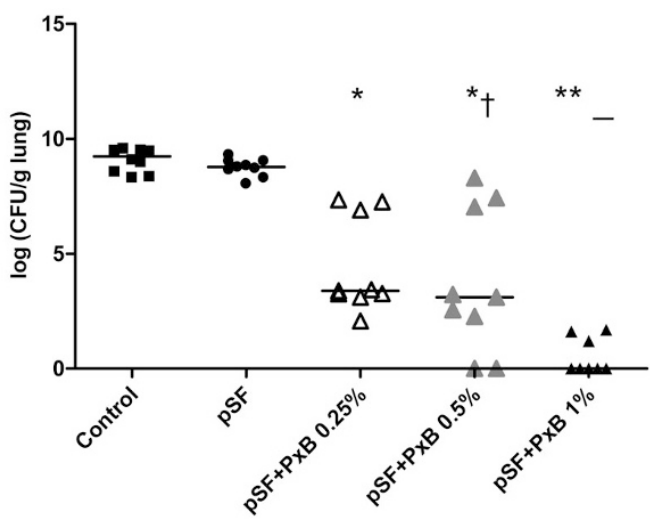

Figure 2. Logarithm of colony-forming units (CFU/g lung) in animals prophylactically receiving saline (control), surfactant $(\mathrm{pSF})$, or $\mathrm{pSF}+\mathrm{PxB}$ $(0.25 \%$ to $1 \%)$ followed by bacterial inoculation of $10^{8} / \mathrm{mL}$ E. coli $(5 \mathrm{~mL} / \mathrm{kg})$ and ventilated for $240 \mathrm{~min}$ with standardized tidal volume of $6-7 \mathrm{~mL} / \mathrm{kg}$. Results were corrected by addition of $1 \mathrm{CFU}$ to enable calculation of the logarithm for those showing total bacterial eradication. $* p<0.01$; $* * p<$ 0.001 vs control; $\dagger p<0.05 ;, p<0.001$ vs pSF (nonparametric KruskalWallis test with Dunn's post-test).

and without any statistical difference. All animals receiving $\mathrm{pSF}+\mathrm{PxB}$ showed a significantly decreased level of inflammation $(p<0.05 v s$ control; Table 3). Inflammation was also found in animals receiving only saline without bacterial inoculation. Severe inflammatory tissue destruction was mainly found in controls and in pSF-treated animals, whereas moderate and mild inflammation, rarely prominent inflammation was found in $\mathrm{pSF} / \mathrm{PxB}$ groups (Fig. 4). The maximum grade of histologic inflammation was not found in the saline, the PxB $1 \%$ or the pSF + PxB groups (Table 3, Figs. $3 C$ and $D$ and 4 ).

\section{DISCUSSION}

We investigated the combined effects of PxB and pSF in an animal model of neonatal Gram-negative pneumonia. The rationale for this study was that neonates often receive both, antibiotics and surfactant, because respiratory failure directly after birth is common and it is difficult to distinguish between pneumonia and respiratory distress syndrome. The study was designed to use prophylactic intratracheal surfactant and/or PxB to assess efficacy of subsequent suppression of $E$. coli proliferation during a short period of mechanical ventilation. For additional comparison, early treatment studies of E. coli inoculation followed by administration of surfactant and/or PxB are needed. Early-onset neonatal sepsis with Gramnegative ampicillin-resistant $E$. coli is an emerging problem among very low birth weight infants $(<1500 \times$ g) since introduction of routine intrapartum antibiotic prophylaxis and prenatal screening for Group-B streptococci (10-12). PxB experiences attention in connection with emergence of multidrug-resistant Gram-negative bacteria $(13,14)$. For early prevention of Gram-negative bacterial translocation by conducting airways and for prevention of bacterial inactivation of surfactant, a combined tracheal instillation of surfactant plus antibiotics could be of use.

The combination of surfactant and antibiotics may cause a change in surfactant and/or antimicrobial activity: van't Veen et al. $(15,16)$ found that antibiotics can affect the in vivo activity of bovine surfactant and that mice infected with Klebsiella pneumoniae showed increased survival after treatment with surfactant-tobramycin mixtures compared with animals treated with only surfactant or with only tobramycin. However, our previous studies demonstrated that addition of PxB to modified pSF increases resistance to surfactant inactivation and maintains antimicrobial activity of PxB (6).

In this study, $E$. coli were nearly eradicated in animals which were treated with $\mathrm{PxB}$ or PxB plus surfactant. This could be caused by a homogenous PxB distribution resulting in an effective topical concentration of PxB. PxB can crosslink between the surfactant phospholipids $(17,18)$ and can be distributed with surfactant homogenously. The administered dose of PxB corresponds to the recommended daily doses of aerosolized PxB $(2.5 \mathrm{mg} / \mathrm{kg} / \mathrm{d})(1)$, but the effective deposited dose may be increased compared with aerosolization when $<5 \%$ of the nebulised drug reach the alveolar space. Furthermore, the PxB concentration used in our study (200-800 $\mu \mathrm{g} / \mathrm{mL}$ ) is 100 - to 400 -fold higher than the minimum in vitro inhibitory concentration against E. coli (ATCC 25922) of liposomal PxB, encapsulated in DPPC:Cholesterol, which was $2 \pm 0.5 \mu \mathrm{g} / \mathrm{mL}$ (19).

PxB has a high affinity to the lipid A moiety of endotoxin (lipopolysaccharide [LPS]). In the absence of LPS in vitro, the surfactant/PxB preparations showed increased resistance to surfactant inactivation with albumin or meconium $(5,20)$. However, in the present investigation, addition of PxB resulted only in an inconsistent improvement in compliance (Tables 1 and 2). Lung compliance can be used as an in vivo parameter of surface activity (3). The factors affecting surfactant activity and surfactant inactivation in this model are complex. The 29-d-old animals used in this study demonstrate poor compliance already in absence of E. coli, although they are near term (term gestation is $31 \mathrm{~d}$ ) and lungs are relatively mature. To some extent poor compliance in this setting might be related to surfactant 
Table 3. Histologically assessed alveolar air expansion that was semiquantitatively estimated by a five-grade scale $(0=0,1=1-25,2=$ $26-50,3=51-75,4=76-100 \%)$, airway epithelial necrosis $(0=$ absent, $1=$ mild, $2=$ moderate, $3=$ prominent $)$ and grade of inflammation, which was estimated by using a five-grade scale $(0=$ absent, $1=$ mild, $2=$ moderate, $3=$ prominent $; 4=$ severe tissue destruction)

\begin{tabular}{|c|c|c|c|}
\hline & Expansion & Airway epithelial necrosis & Inflammation \\
\hline \multicolumn{4}{|c|}{$\begin{array}{l}\text { Animals treated with pSF and/or PxB } 1 \% \text { compared with control animals and animals receiving } \\
\text { twice saline and no bacteria (saline) }\end{array}$} \\
\hline Saline & $1(0-4)$ & $3(0-3)$ & $2(1-3)$ \\
\hline Control & $1(0-3)$ & $1(0-3)$ & $3(2-4)$ \\
\hline PxB $1 \%$ & $1(0-4)$ & $1(1-3)$ & $1.5(1-4)$ \\
\hline $\mathrm{pSF}$ & $3(2-4) *$ & $1(0-2)$ & $3(1-4)$ \\
\hline$+\mathrm{PxB} 1 \%$ & $3(1-4)^{*}$ & $0(0-3)$ & $1(0-3)^{*} \dagger$ \\
\hline \multicolumn{4}{|c|}{ Animals treated with $\mathrm{pSF} \pm \mathrm{PxB}(0.25-1 \%)$ compared with control animals } \\
\hline Control & $2(1-3)$ & $3(0-3)$ & $4(3-4)$ \\
\hline $\mathrm{pSF}$ & $3(2-4)$ & $0(0-2)$ & $3(1-4)$ \\
\hline$+\mathrm{PxB} 0.25 \%$ & $3(2-4) *$ & $0(0-2)$ & $2(1-3)^{*}$ \\
\hline$+\mathrm{PxB} 0.5 \%$ & $3(2-4) *$ & $0(0-3)$ & $3(1-3)^{*}$ \\
\hline$+\mathrm{PxB} 1 \%$ & $2.5(1-4)$ & $0(0-3)$ & $2(0-3)^{*}$ \\
\hline
\end{tabular}

Results are given as median and range.

$* p<0.05$ vs control animals.

$\dagger p<0.05$ vs pSF (Kruskal-Wallis test followed by Dunn's multiple comparison test).

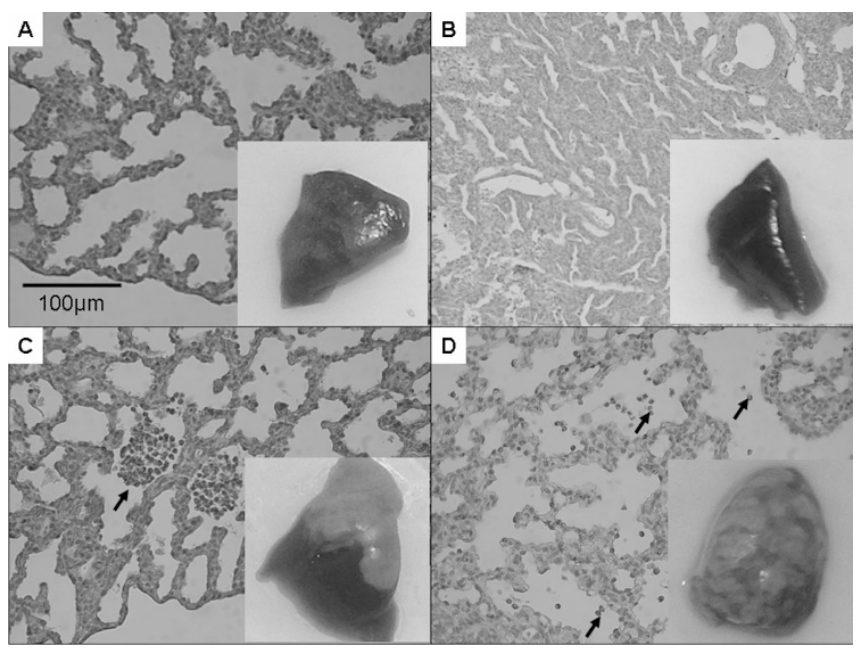

Figure 3. Macroscopical appearance and representative histologic sections of ventilated near-term neonatal rabbits with $E$. coli pneumonia after treatment with pSF ( $A$ : well expanded, mild inflammation), control ( $B$ : atelectasis), $\mathrm{pSF} / \mathrm{PxB} 0.25 \%$ (wt/wt) (C: aggregated alveolar inflammatory cells), and $\mathrm{pSF} / \mathrm{PxB} 1 \%$ (wt/wt) (D: well expanded, moderate inflammation). Control animals showed atelectatic lungs compared with more expanded lungs and alveoli in PxB- \pm pSF-treated animals. The latter lungs demonstrated an inflammatory reaction with loose or aggregated neutrophilic cells, as demonstrated in the histologic sections (arrows), that was not suppressed by increasing $\mathrm{PxB}$ concentrations.

dilution of E. coli or saline with $5 \mathrm{~mL}$ fluid per $\mathrm{kg}$ body weight. A LPS challenge similar to our pneumonia model based on E. coli inoculation resulted in an inconsistent response in adult rats although identical doses of LPS were used (4). This could additionally contribute to the observed variability in compliance of animals that received E. coli. Furthermore, bacterial enzymes, which induce breakdown of surfactant components (21), may contribute to surfactant inactivation.

Our histologic evaluation clearly shows an influx of inflammatory cells in lungs treated with $E$. coli regardless of addition of PxB. PxB causes cytolysis of Gram-negative bacteria by inducing pore formation in the membranes.

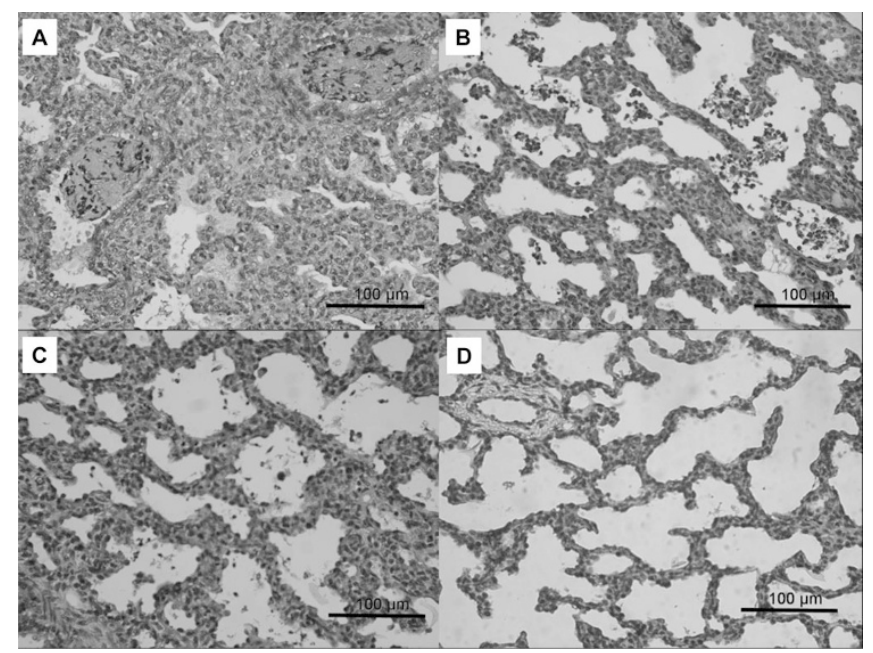

Figure 4. Example of a control lung $(A)$ showing atelectasis, inflammatory tissue destruction and severe airway epithelial necrosis compared with a pSF lung $(B)$ with moderate inflammation and $\mathrm{pSF} / \mathrm{PxB}$-treated lungs with moderate $(C)$ and mild inflammation $(D)$.

Thus, LPS and bacterial wall components still are present in the alveoli and act as a powerful proinflammatory agent inducing an increase of vascular permeability, neutrophilic alveolitis, septic shock, and ARDS (22,23). The intensity of systemic inflammatory and physiologic responses to intrapulmonary Gram-negative infection depends on the inoculum size and whether the bacteria are cleared from or proliferate in the lungs (24). In addition, the inflammation also might be triggered to some degree by mechanical ventilation (25). We also found inflammation and atelectasis in only saline-treated animals. Presumably, the atelectrauma of only saline-treated animals cannot be distinguished from the E. coli or endotoxin-induced inflammatory response. To reduce ventilator injury, the study was designed to use a low standardized $V_{\mathrm{T}}$ of $6-7 \mathrm{~mL} / \mathrm{kg}$ body weight, which is recommended in ARDS (26). However, we did not apply any PEEP. van Kaam (27) concluded from animal experiments that an open-lung ventilation strategy 
including PEEP in a model of GBS pneumonia is more important in attenuating inflammatory response than surfactant treatment. Lachmann et al. (28) showed a reduced bacterial translocation in an ARDS model of GBS pneumonia in animals receiving surfactant and ventilated with an open lung concept. Although our ventilation concept resulted in low compliance, atelectasis, and low alveolar air expansion, it is even more surprising that addition of $\mathrm{PxB}$ resulted in effective prevention of systemic bacterial translocation. PxB alone or synthetic derivates thereof, due to high affinity to LPS, have been used in animal experiments and clinical trials to neutralize endotoxin $(29,30)$. Also, natural surfactant can reduce inflammation. Natural endogenous surfactant as a part of the innate immune system mitigates LPS effects, e.g. by binding LPS with SP-C, SP-A, and SP-D $(31,32)$. The latter proteins are not found in clinically used modified natural surfactants such as Alveofact, Curosurf, or Survanta. However, SP-A and SP-D might be present in near-term neonatal rabbits although to a different extent. In this case, presence of SP-A enhances LPS binding and degradation by alveolar macrophages (33). Curosurf treatment alone decreased mortality, pulmonary edema, and inflammation in spontaneously breathing rats with ARDS induced by intratracheal LPS injection (34). Inflammatory effects may also be reduced by surfactant by suppressing cytokine secretion, mitogen-driven proliferation, neutrophil influx, and immunoglobulin production $(35,36)$.

In this study, we found a high rate of early death in all treatment groups. In a similar model of GBS pneumonia in near-term rabbits, in which animals were ventilated with higher $V_{\mathrm{T}}(8-10 \mathrm{~mL} / \mathrm{kg})$ and a prolonged inspiration time, survival was increased (37). In comparison, a high rate of early death due to GBS pneumonia was found in newborn piglets with conventional ventilation compared with openlung ventilation (28).

In this study, PxB was given topically onto the inner surface of the lung. Although PxB does not appear to be reabsorbed by the skin or gastrointestinal mucosa (1), it might be resorbed through inflammatory lesions of the conducting airways. We did not measure PxB reabsorption in animals. Omri et al. (19) used a similar preparation in which PxB was encapsulated in liposomes of DPPC and cholesterol, for topical pulmonary treatment in a rat model of chronic Gram-negative pneumonia and found decreased inflammatory lung injury and nondetectable levels of PxB in serum and the kidney, although $\mathrm{PxB}$ is primarily excreted through the kidney. Liposomal formulations delivered into the lung might cause sustained drug release and thereby low serum and tissue levels of PxB. Thus, the risk of toxic effects might be less compared with treatment with PxB alone (19).

The main result of this study was that intratracheal administration of $\mathrm{pSF} / \mathrm{PxB}$ mixtures exerts potent antibacterial effects. Surfactant/PxB mixtures reduced bacterial translocation to the systemic circulation and mitigated the inflammatory reaction in the lungs. We speculate that by optimizing the ventilation strategy in our model, the level of inflammation could be further decreased and early death might be prevented.
In conclusion, intratracheal instillation of $\mathrm{pSF} / \mathrm{PxB}$ mixtures in neonatal near-term rabbits reduces bacterial growth in the lungs and prevents bacterial sepsis without exerting negative effects on lung function. This treatment cannot prevent a pulmonary inflammatory response because endotoxin exposure is still present. Further studies investigating mature and immature neonates with Gram-negative pneumonia and studying physiologic and toxicological data $\left(\mathrm{as}^{\mathrm{PaO}_{2}}\right.$, blood gas analysis, $\mathrm{PxB}$ elimination) during open-lung ventilation are needed, before the safety of a pSF/PxB combination can be assessed in a clinical setting.

\section{REFERENCES}

1. Sarkar S, DeSantis ER, Kuper J 2007 Resurgence of colistin use. Nephrotoxic, neurotoxic effects of polymyxins. Am J Health Syst Pharm 64:2462-2466

2. Falagas ME, Kasiakou SK 2006 Toxicity of polymyxins: a systematic review of the evidence from old and recent studies. Crit Care 10:R27

3. Robertson B, Schürch S 1998 Assessment of surfactant function. In: Uhlig S, Taylor AE (eds) Methods in Pulmonary Research. Birkäuser Verlag, Basel, Switzerland, pp 349-383

4. Taeusch HW, Keough KM 2001 Inactivation of pulmonary surfactant and the treatment of acute lung injuries. Pediatr Pathol Mol Med 20:519-536

5. Taut FJ, Rippin G, Schenk P, Findlay G, Wurst W, Häfner D, Lewis JF, Seeger W, Günther A, Spragg RG 2008 A Search for subgroups of patients with ARDS who may benefit from surfactant replacement therapy: a pooled analysis of five studies with recombinant surfactant protein-C surfactant (Venticute). Chest 134:724-732

6. Stichtenoth G, Jung P, Johansson J, Robertson B, Curstedt T, Herting E 2006 Polymyxin B/pulmonary surfactant mixtures have increased resistance to inactivation by meconium and reduce growth of Gram-negative bacteria in vitro. Pediatr Res 59:407-411

7. Sun B, Kobayashi T, Cursted T, Grossmann G, Robertson B 1991 Application of a new ventilator-multi-plethysmograph system for testing efficacy of surfactant replacement in newborn rabbits. Eur Respir J 4:364-370

8. Stichtenoth G, Linderholm B, Almlén A, Björkman MH, Byman I, Nordling K, Robertson B, Johansson J, Herting E, Curstedt T 2009 Inactivation of pulmonary surfactant by silicone oil in vitro and in ventilated immature rabbits. Crit Care Med $37: 1750-1756$

9. Johansson J, Some M, Linderholm BM, Almlén A, Curstedt T, Robertson B 2003 A synthetic surfactant based on a poly-Leu SP-C analog and phospholipids: effects on tidal volumes and lung gas volumes in ventilated immature newborn rabbits. J Appl Physiol 95:2055-2063

10. Stoll BJ, Hansen NI, Higgins RD, Fanaroff AA, Duara S, Goldberg R, Laptook A Walsh M, Oh W, Hale E 2005 National Institute of Child Health and Human Development: very low birth weight preterm infants with early onset neonatal sepsis: the predominance of Gram-negative infections continues in the National Institute of Child Health and Human Development Neonatal Research Network 2002-2003. Pediatr Infect Dis J 24:635-639

11. Stoll BJ, Hansen N, Fanaroff AA, Wright LL, Carlo WA, Ehrenkranz RA, Lemons JA, Donovan EF, Stark AR, Tyson JE, Oh W, Bauer CR, Korones SB, Shankaran S, Laptook AR, Stevenson DK, Papile LA, Poole WK 2002 Changes in pathogens causing early-onset sepsis in very-low-birth-weight infants. N Engl J Med 347:240247

12. Schrag SJ, Stoll BJ 2006 Early-onset neonatal sepsis in the era of widespread intrapartum chemoprophylaxis. Pediatr Infect Dis J 25:939-940

13. Falagas ME, Kasiakou SK 2005 Colistin: the revival of polymyxins for the management of multidrug-resistant Gram-negative bacterial infections. Clin Infect Dis 40:1333-1341

14. Evans ME, Feola DJ, Rapp RP 1999 Polymyxin B sulfate and colistin: old antibiotics for emerging multiresistant Gram-negative bacteria. Ann Pharmacother 33:960-967

15. van't Veen A, Mouton JW, Gommers D, Lachmann B 1996 Pulmonary surfactant as vehicle for intratracheally instilled tobramycin in mice infected with Klebsiella pneumoniae. Br J Pharmacol 119:1145-1148

16. van 't Veen A, Gommers D, Mouton JW, Kluytmans JA, Krijt EJ, Lachmann B 1996 Exogenous pulmonary surfactant as a drug delivering agent: influence of antibiotics on surfactant activity. Br J Pharmacol 118:593-598

17. Cajal Y, Ghanta J, Easwaran K, Surolia A, Jain MK 1996 Specificity for the exchange of phospholipids through polymyxin B mediated intermembrane molecular contacts. Biochemistry 35:5684-5695

18. Zaltash S, Palmblad M, Curstedt T, Johansson J, Persson B 2000 Pulmonary surfactant protein B a structural model and a functional analogue. Biochim Biophys Acta 1466:179-186

19. Omri A, Suntres ZE, Shek PN 2002 Enhanced activity of liposomal polymyxin B against Pseudomonas aeruginosa in a rat model of lung infection. Biochem Pharmacol 64:1407-1413

20. Calkovska A, Some M, Linderholm B, Johansson J, Curstedt T, Robertson B 2005 Biophysical and physiological properties of porcine surfactant enriched with polymyxin B. Biol Neonate 88:101-108 
21. Flieger A, Gongab S, Faigle M, Mayer HA, Kehrer U, Mussotter J, Bartmann P, Neumeister B 2000 Phospholipase A secreted by Legionella pneumophila destroys alveolar surfactant phospholipids. FEMS Microbiol Lett 188:129-133

22. Wheeldon EB, Walker ME, Murphy DJ, Turner CR 1992 Intratracheal aerosolization of endotoxin in the rat: a model of the adult respiratory distress syndrome (ARDS). Lab Anim 26:29-37

23. van Helden HP, Kuijpers WC, Steenvoorden D, Go C, Bruijnzeel PL, van Eijk M, Haagsman HP 1997 Intratracheal aerosolization of endotoxin (LPS) in the rat: a comprehensive animal model to study adult (acute) respiratory distress syndrome. Exp Lung Res 23:297-316

24. Fox-Dewhurst R, Alberts MK, Kajikawa O, Caldwell E, Johnson MC II, Skerrett SJ, Goodman RB, Ruzinski JT, Wong VA, Chi EY, Martin TR 1997 Pulmonary and systemic inflammatory responses in rabbits with gram-negative pneumonia. Am J Respir Crit Care Med 155:2030-2040

25. Tremblay LN, Slutsky AS 1998 Ventilator-induced injury: from barotrauma to biotrauma. Proc Assoc Am Physicians 110:482-488

26. Uhlig S, Frerichs I 2008 Lung protective ventilation-pathophysiology and diagnostics. Anasthesiol Intensivmed Notfallmed Schmerzther 43:438-445

27. van Kaam AH, Lutter R, Lachmann RA, Haitsma JJ, Herting E, Snoek M, De Jaegere A, Kok JH, Lachmann B 2005 Effect of ventilation strategy and surfactant on inflammation in experimental pneumonia. Eur Respir J 26:112-117

28. Lachmann RA, van Kaam AH, Haitsma JJ, Lachmann B 2007 High positive end-expiratory pressure levels promote bacterial translocation in experimental pneumonia. Intensive Care Med 33:1800-1804
29. Danner RL, Joiner KA, Rubin M, Patterson WH, Johnson N, Ayers KM, Parrillo JE 1989 Purification, toxicity, and antiendotoxin activity of polymyxin B nonapeptide. Antimicrob Agents Chemother 33:1428-1434

30. Manocha S, Feinstein D, Kumar A, Kumar A 2002 Novel therapies for sepsis: antiendotoxin therapies. Expert Opin Investig Drugs 11:1795-1812

31. van Rozendaal BA, van de Lest CH, van Eijk M, van Golde LM, Voorhout WF, van Helden HP, Haagsman HP 1999 Aerosolized endotoxin is immediately bound by pulmonary surfactant protein D in vivo. Biochim Biophys Acta 1454:261-269

32. Ikegami M, Carter K, Bishop K, Yadav A, Masterjohn E, Brondyk W, Scheule RK, Whitsett JA 2006 Intratracheal recombinant surfactant protein D prevents endotoxin shock in the newborn preterm lamb. Am J Respir Crit Care Med 173:1342-1347

33. Stamme C, Wright JR 1999 Surfactant protein A enhances the binding and deacylation of E. coli LPS by alveolar macrophages. Am J Physiol 276:L540-L547

34. van Helden HP, Kuijpers WC, Langerwerf PE, Langen RC, Haagsman HP, Bruijnzeel PL 1998 Efficacy of Curosurf in a rat model of acute respiratory distress syndrome. Eur Respir J 12:533-539

35. Thomassen MJ, Meeker DP, Antal JM, Connors MJ, Wiedemann HP 1992 Synthetic surfactant (Exosurf) inhibits endotoxin-stimulated cytokine secretion by human alveolar macrophages. Am J Respir Cell Mol Biol 7:257-260

36. Thomassen MJ, Antal JM, Barna BP, Divis LT, Meeker DP, Wiedemann HP 1996 Surfactant downregulates synthesis of DNA and inflammatory mediators in normal human lung fibroblasts. Am J Physiol 270:L159-L163

37. Herting E, Jarstrand C, Rasool O, Curstedt T, Sun B, Robertson B 1994 Experimental neonatal group B streptococcal pneumonia: effect of a modified porcine surfactant on bacterial proliferation in ventilated near-term rabbits. Pediatr Res 36:784-791 